\title{
O PAPEL DAS ACELERADORAS NA CONSOLIDAÇÃO DE NOVAS EMPRESAS DE CULTURA EMPREENDEDORA A LUZ DA METODOLOGIA LEAN STARTUP
}

\author{
M. R. C. SARMENTO* e L. F. L. G. COSTA \\ Instituto Federal de Educação, Ciência e Tecnologia do Rio Grande do Norte \\ marcelaregina.cs@gmail.com*
}

Artigo submetido em abril/2016 e aceito em junho/2016

DOI: 10.15628/empiricabr.2016.4437

\section{RESUMO}

O presente estudo se propõe a analisar o papel das aceleradoras na consolidação de novas empresas de cultura empreendedora a luz da metodologia Lean Startup. Para tal foi realizada uma pesquisa qualitativa de tipo exploratória, descritiva e explicativa, utilizando como estratégia de pesquisa o estudo de caso. A coleta de dados consistiu em uma entrevista semiestruturada com a aceleradora de negócios 85 Labs com o intuito de verificar a aplicabilidade da metodologia lean startup na orientação e assessoria de novos empreendimentos. A pesquisa descreve ainda como se dá o ciclo de aceleração e a relação entre as startups e a aceleradora observando as dificuldades desse processo e os benefícios desse relacionamento. Os resultados obtidos foram satisfatórios à medida que constataram que as aceleradoras de negócios exercem um papel decisivo no desenvolvimento e consolidação de novas empresas de cultura empreendedora, visto que o processo de aceleração direciona e capacita as startups principalmente nas primeiras etapas do negócio, onde os riscos são consideravelmente maiores. Além disso, durante a análise ficou evidente a contribuição da metodologia lean startup em todas as fases do ciclo de aceleração, o que permitiu afirmar sua capacidade em conduzir processos estruturados de aceleração em negócios com eficácia em caso real.

PALAVRAS-CHAVE: Lean startup, aceleradora de negócios, startups, empreendedorismo.

\section{THE ROLE OF THE BUSINESS ACCELERATORS TO CONSOLIDATION THE NEW COMPANIES OF CULTURE ENTREPRENEURIAL IN VIEW OF METHODOLOGY LEAN STARTUP}

\begin{abstract}
This study aims to analyze the role of accelerating the consolidation of new companies in an entrepreneurial culture in light of the Lean Startup methodology. To this end it was made of a qualitative exploratory, descriptive and explanatory, using as research strategy case study. Data collection consisted of a semi-structured interview with the accelerator business 85 Labs in order to verify the applicability of the lean startup methodology in guiding and advising new ventures. The survey also describe, how is the acceleration cycle and the relationship between startups and accelerator noting the difficulties of this process and the benefits of that
\end{abstract}

relationship. The results were satisfactory in that it found that the business accelerator play a decisive role in the development and consolidation of new companies in an entrepreneurial culture, since the process of acceleration directs and empowers startups mainly in the early stages of business where the risks they are considerably higher. In addition, during the analysis, the startup lean methodology contribution was evident in all phases of acceleration cycle, which allowed us to affirm their ability to conduct structured processes acceleration in business with real case effectively.

KEYWORDS: Lean Startup, business accelerators, startups, entrepreneurial. 


\section{INTRODUÇÃO}

Os conceitos de inovação e empreendedorismo têm se tornado cada dia mais populares. Segundo o Global Entrepreneurship Monitor ${ }^{1}$ (2013), no Brasil cerca de 40 milhões de pessoas estão empreendendo, o que coloca o país na quarta posição do ranking mundial em número absoluto de empreendedores, atrás da China, Índia e Nigéria. A perspectiva de novos empreendimentos tem sido de importância estratégica para economia nacional. Dornelas (2001) aponta o empreendedorismo como um forte aliado para o desenvolvimento econômico, principalmente pelo suporte às inovações de mercado que tem oferecido. Investir em um ambiente que propicie novas ideias de projetos significa promover uma economia sustentável, eficiente e inovadora, com efeitos diretos nos índices de empregabilidade, renda e produto interno bruto.

Nesse contexto, o desejo de tirar boas ideias do papel e transforma-las em realidade e os atuais exemplos de startups bem sucedidas como: Facebook, Peixe Urbano, Groupon, Easy Taxi e BuscaPé têm inspirado empreendedores diariamente a iniciarem seus projetos. A Associação Brasileira de Startups (2015) conceitua startup como uma empresa de base tecnológica, que busca desenvolver um modelo de negócio repetível e escalável, utilizando elementos de inovação e operando em condições de extrema incerteza.

Justamente por essas condições, o investimento em uma startup é considerado de alto risco, levando em consideração a imprevisibilidade da aceitação do produto ou serviço no mercado e sua viabilidade comercial. Apesar de fundamental, o acesso ao capital, contudo, não é único fator decisivo para o sucesso de uma startup. Mesmo desenvolvendo uma ideia inovadora, muitas não possuem a expertise, rede de contatos ou conhecimentos de gestão necessários para se inserirem no mercado de forma eficaz.

É sobre essa perspectiva que se encontram as aceleradoras, foco principal desse projeto de pesquisa. Nascidas no Vale do Silício, o "thing thank" dos empresários da indústria de software, as aceleradoras são organizações financiadas com capital privado com o objetivo de fomentar o crescimento de startups em um curto espaço de tempo. Com alto poder de crescimento, essas empresas de investimentos oferecem além de aporte financeiro, apoio estratégico, baseado principalmente na criação e desenvolvimento do negócio. Por meio de um programa intensivo e em troca de participação acionária, as aceleradoras fornecem toda a assessoria necessária para a aceleração de novos empreendimentos. Além disso, o contato startup - aceleradora tem fundamental importância na inserção dessas novas empresas no "ecossistema" empreendedor, facilitando a criação de networking e potenciais oportunidades.

Para alcançar o sucesso na aceleração de startups, cada aceleradora determina os melhores métodos que irá utilizar. Eles representam os planos de trabalho a serem cumpridos dentro do tempo determinado para aceleração de cada novo empreendimento. É nesse contexto que se destaca a metodologia Lean Startup. Formulada a partir da combinação de ideias de marketing,

\footnotetext{
${ }^{1}$ O Global Entrepreneurship Monitor - GEM é um programa de pesquisa de abrangência mundial que tem o objetivo de avaliar o nível da atividade empreendedora;
} 
gestão e tecnologia, o conceito Lean ou "enxuto" preconizado por Eric Ries ${ }^{2}$ e Steve Blank ${ }^{3}$ representa um conjunto de novas práticas para criação de empresas nascentes.

Ambos compactuam da ideia de que em um ecossistema empreendedor constantemente mutável e com maiores riscos e incertezas, os tradicionais métodos de gestão não são eficazes, pois se baseiam em previsões, funcionando melhor em ambientes estáticos. Não obstante, Lean Startup configura um novo empírico método, focado na redução do desperdício (tempo, custo ou recursos) e validação de hipóteses na busca por um negócio escalável e repetível por meio da experimentação e de feedbacks contínuos com o cliente (RIES, 2012), a fim de conferir ao produto ou serviço maior qualidade e um time-to-market ${ }^{4}$ mais rápido.

Diante desse contexto, e considerando a relevância do assunto exposto para o ecossistema empreendedor e a atual escassez de pesquisas acadêmicas sobre a metodologia Lean Startup e sua aplicação no ambiente das aceleradoras, esta pesquisa apresenta um estudo de caso, do qual tem por tema: O papel das aceleradoras na consolidação de novas empresas de cultura empreendedora a luz da metodologia Lean Startup. Tendo como objeto de análise dessa pesquisa, a aceleradora 85 Labs. Dessa forma, a implementação deste estudo de caso será conduzida através de visita técnica a aceleradora 85 Labs, da qual consistirá na análise das informações obtidas por meio de entrevista semiestruturada, tendo como orientação para esta análise as categorias: Visão, Direção e Aceleração ${ }^{5}$, as quais foram subdivididas a fim de incorporar as diversas fases de desenvolvimento de negócios, orientadas de acordo com os principais conceitos da metodologia Lean Startup.

Definiu-se, portanto, como objetivo geral de pesquisa - analisar o papel das aceleradoras na consolidação de novas empresas de cultura empreendedora a luz da metodologia Lean Startup. Em relação aos objetivos específicos, foram estabelecidas três principais metas, objetivando a compreensão do cenário exposto: a) identificar os benefícios resultantes da relação startup aceleradora; b) descrever como se dá o processo de aceleração de negócios, bem como as dificuldades enfrentadas pelas startups nesse percurso do ponto de vista da aceleradora; c) verificar a convergência teórica da metodologia lean startup aplicada à aceleradora na orientação e assessoria dos novos empreendimentos sobre a ótica da inovação e do empreendedorismo.

A ideia de realizar esse projeto de pesquisa partiu do interesse do pesquisador em estudar aceleradoras e em particular a metodologia Lean Startup e sua aplicação. A importância desse trabalho se justifica pela necessidade de se obter informações relevantes sobre esse contexto, de forma a agregar conhecimento à literatura disponível. Embora que a metodologia lean startup esteja ganhando maior ênfase, o que se identifica atualmente é uma escassez de investigações acadêmicas sobre o método (GUSTAFSSON; QVILLBERG, 2012). Tais inconsistências se intensificam quando se referem a estudos empíricos com vistas à avaliação da sua aplicabilidade no ecossistema empreendedor, da qual estão inseridas aceleradoras e startups. Prioritariamente, o tema aceleradoras de negócios tem despertado o interesse de pesquisadores e em sua maioria

\footnotetext{
${ }^{2}$ Eric Ries é um empreendedor do Vale do Silício e autor, reconhecido por ser o criador do movimento Lean Startup;

${ }^{3}$ Steve Blank é professor, criador da metodologia Customer Development, que lançou as bases para o movimento Lean Startup. Atualmente é reconhecido como um dos mais renomados especialistas em empreendedorismo no Vale do Silício, além de ser fundador de diversas startups;

${ }^{4}$ Time-to-market é uma expressão que se refere ao tempo de um produto ou serviço, que inicia com a concepção do conceito e termina quando o mesmo está disponível para comercialização.

${ }^{5}$ Em sua obra "A Startup Enxuta" Eric Ries utiliza essa divisão para descrever a metodologia Lean startup em três etapas específicas.
} 
estudiosos internacionais ${ }^{6}$, que tem contribuído para um maior entendimento a cerca desse conceito relativamente novo.

Não obstante, esta pesquisa busca suprir a lacuna teórica existente na pesquisa acadêmica atual, promovendo a junção desses dois elementos de inovação: o método lean startup e as aceleradoras de negócios. Com a finalidade de obter respostas consistentes, em um caso real, sobre a aplicabilidade dessa metodologia em processos de aceleração em negócios. Espera-se que os resultados obtidos nessa pesquisa possam contribuir para o meio acadêmico, novos empreendedores e outros interessados na compreensão do assunto estudado.

\section{REFERÊNCIAL TEÓRICO}

Nessa sessão, é apresentada a fundamentação teórica da qual se baseia esta pesquisa.

\subsection{Da ideia à execução}

No auge da bolha das "pontocom" ${ }^{7}$, o cenário era de supervalorização de ideias. A ampla disponibilidade de capital de risco e o progressivo aumento dos preços das ações propiciaram um ambiente favorável às nascentes do setor. Motivados pela possibilidade de lucros futuros, investidores de risco ignoraram os tradicionais métodos de avaliação de ativos e apostaram em novas empresas baseadas na internet. Alguns anos mais tarde, após o estouro da bolha, o que restou foi o ônus da redução drástica de investimentos de risco, que resultou em insuficiência financeira aos novos empreendimentos (MITCHELL, 2010 apud CASEMIRO, 2014). Desde então, a cautela por parte dos investidores e a reconfiguração do mercado, trouxeram à tona o questionamento sobre o real valor da ideia na consolidação de novos projetos.

Para Drucker (1986, p. 256): A organização inovadora compreende que a inovação começa com uma ideia, estimula e orienta os esforços para transformar uma ideia num produto, num processo, numa empresa ou numa tecnologia. Segundo Aristóteles (1984), filósofo grego, grande pensador de ideias sobre a humanidade, em sua obra Ética a Nacômaco, indaga que é preciso pensar antes de agir, mas principalmente, se faz necessário o agir depois do pensamento. Assim, a ação sem o pensamento é perigosa e o pensamento sem ação se torna inócuo (ARISTÓTELES, 1984 apud MUSSAK, 2012). Ainda de acordo com Barbieri (1999), o ato de inovar não se restringe a desenvolver apenas uma ideia genial, mas sim, colocá-la em prática após identificar oportunidades. "A oportunidade é a fonte da inovação" (DRUCKER, 2002, p. 93). Dessa forma, sem execução uma ideia não ascende além da intenção. $O$ elo perdido entre a ideia e o resultado seria a atitude (CHARAN, 2003 apud MUSSAK, 2012).

Seguindo esse embasamento, o concerne da ideia inovadora está em contribuir de maneira efetiva para mercado e seus consumidores. A necessidade é a mãe da invenção (DRUCKER, 2002, p. 93). Para Hill e Powers (1999), a riqueza vem de transformar esta ideia, de um abstrato que temos na nossa mente, em algo que seja útil às pessoas. Sobre essa perspectiva, Ries (2012) afirma que a principal atividade de uma startup é transformar ideias em produtos viáveis. A Associação Brasileira de Startups - AB Startups (2015) conceitua startup como uma empresa de base

\footnotetext{
${ }^{6}$ Por exemplo: Barrehag et al. 2012, Casemiro et al. 2014, Fishback et al. 2007, Miller; Bound, 2011.

7 O termo bolha das "ponto.com" se refere a crise que eclodiu mundialmente em 2001 culminando com o fechamento e redução de um grande número dos negócios digitais da época.
} 
tecnológica, que busca desenvolver um modelo de negócio repetível e escalável, utilizando elementos de inovação e operando em condições de extrema incerteza.

Para Drucker (2002, p. 25) "A inovação é o instrumento específico dos empreendedores, o meio pelo qual eles exploram a mudança como uma oportunidade para um negócio diferente ou um serviço diferente". Victorazzo et al. (2014) afirma que o destaque da criação de novos negócios (startups) no cenário atual vincula-se a um intenso processo de "destruição criativa", onde as atuais estruturas vigentes dão lugar a novos produtos/processos/empresas, que por sua vez, reconfiguram o status-quo do mercado. Diretamente associadas aos conceitos de empreender e inovar as startups refletem as tendências globais. Sobre isso, Dornelas (2001) entende que a dinâmica atual demanda por empresas mais ágeis e flexíveis que possam responder efetivamente frente às necessidades do mercado. Rivoli (2005 apud Silva, 2013) associa a agitada dinâmica dos mercados a processos biológicos, considerando que nesse ambiente a predominância fica sempre a cargo dos mais aptos.

Segundo a AB Startups (2014) cerca de nove em cada dez startups literalmente "quebram" ainda na fase de desenvolvimento inicial. Estreantes no mercado, muitas dessas empresas não dominam conhecimentos de gestão ou simplesmente não entendem a mecânica de investimentos. Um recente estudo da Harvard Business School desenvolvido por Shikhar Ghosh confirma que 75\% dos novos empreendimentos não vingam (BLANK, 2014). De acordo com o IBGE (2014) 49\% das empresas fecham as portas devido a problemas financeiros e de gestão. $O$ investimento, independente do montante, precisa ser bem alocado e planejado. Além disso, em sua maioria, essas novas empresas não possuem experiência, investidores ou clientes. Sem uma orientação, assessoria ou um rápido e efetivo modelo de negócios, as chances de fracasso dessas startups são muito significativas.

\subsection{As aceleradoras}

Há muito têm se falado sobre como apoiar de forma efetiva o desenvolvimento de projetos inovadores. Sobre essa perspectiva um novo conceito em particular tem obtido grande destaque na indústria de capital risco, as "seed acelerators". De acordo com Miller e Bound (2011) em sua obra "The startup factories: The rise of accelerator programmes to support new technology ventures", o conceito por trás dos programas de aceleração surgiu como um novo método para a incubação de startups de base tecnológica. Segundo Barrehag et al. (2012) o desenvolvimento de uma startup em processo de incubação era demasiado extenso, podendo levar vários anos até que as novas empresas desenvolvessem os pré-requisitos necessários para estabelecerem no mercado.

Além disso, como foi já foi visto, com o estouro da bolha e o colapso da NASDAC vários investidores perderam seu capital em projetos incubados que não chegaram a gerar qualquer valor. Sobre essa perspectiva, muitos passaram a criticar o modelo até então adotado pelas "incineradoras", termo criado para representar os problemas em investir capital, sem exigir resultados mensuráveis (MILLER; BOUND, 2011). Consequentemente, grande parte dos investidores de "venture capital" apreensivos às mudanças e mais avessos aos riscos inerentes aos seed investiments abandonaram o mercado de empresas em fase inicial, mesmo que isto acarretasse menor lucratividade. Sobre o assunto, Fishback et al. (2007) aponta que do período de

\footnotetext{
${ }^{8}$ Termo usado para descrever todas as classes de investidores de risco.
} 
2000 à 2005, as seed ronds realizadas por VC's passaram de 281 (duzentos e oitenta e uma) para apenas 63 (sessenta e três). Em contra partida, vislumbrando a existência de uma "lacuna de financiamento", business angels ${ }^{9}$ logo absorveram parte dessa demanda por capital. Porém a maioria deles não suportava atender um alto volume em financiamentos simultâneos como até então faziam os VC's (FISHBACK et al. 2007).

Não obstante, ideias como ciclos de incubação mais curtos, custos de investimento e estruturas menores ganharam a atenção de investidores que buscavam um modelo mais efetivo para o desenvolvimento de startups digitais. (BARREHAG et al. 2012). Sobre essa perspectiva surgiram os alicerces para a formação das primeiras aceleradoras de negócios. De acordo com Miller e Bound (2011) foi a partir de exemplos de perfis de alto sucesso como o da aceleradora $Y$ Combinator, fundada em 2005 por Paul Graham nos EUA, que os programas de aceleração cresceram progressivamente, partindo dos Estados Unidos à Europa até se espalharem ao redor do mundo. Segundo Fishback et al. (2007) as aceleradoras são instituições compostas por grupos de pessoas, geralmente empresários experientes, que fornecem muito além do que serviços espaciais e de gestão.

O acelerador se torna a "nova empresa", oferecendo orientação, mentoria, networking, conhecimento e expertise para novos empreendimentos, com o objetivo de ajudá-los a obter sucesso nas primeiras etapas do negócio, onde os riscos são consideravelmente maiores. Para Miller e Bound (2011) o aspecto geral de um programa de aceleração está em possibilitar o contato direto dos fundadores de startups com investidores experientes e outros profissionais de knowhow. Assim como os capitalistas de risco, as aceleradoras possuem alianças com outras empresas específicas com as quais elas estão familiarizadas e possuem boas referências (CASEMIRO et al. 2014, p.02). Essas conexões têm um efeito positivo sobre o ecossistema empreendedor, representando um ponto focal de aprendizagem, troca de informações e confiança às partes envolvidas. (MILLER; BOUND, 2011). Para Casemiro et al. (2014, p. 01) o principal objetivo por trás do surgimento das aceleradoras vem da necessidade de criar um sistema ideal para o desenvolvimento, crescimento e inserção no mercado de empresas nascentes, de forma que estas possam ser consolidadas.

Barrehag et al. (2012) aponta que para existência do programa de aceleração se faz necessária à interação de três principais atores: startups, investidores e mentores. Sendo o investidor elemento principal, para o qual a aceleradora fornece um serviço. Dos quais investidores anjo e capitalistas de risco são o tipo de investidores, mais recorrentes no contexto acelerador. Acerca do serviço de mentoring CRA-SP (2009, p. 09) afirma consistir em "uma relação sistemática ou não, onde o mentor com base em suas experiências e maturidade (profissional e pessoal), indica linhas de atuação facilitando, estimulando e acompanhando o desenvolvimento do indivíduo ou cliente".

Nesse contexto, existe um consenso entre alguns estudiosos da literatura acerca das principais características das quais se configuram o atual modelo de aceleração, conforme apontam Miller e Bound (2011) e corrobora Barrehag et al. (2012):

a) processo de aplicação aberto a todos, porém altamente competitivo;

\footnotetext{
9 Termo na língua inglesa comumente utilizado no universo empreendedor pra se referir à pessoas físicas com conhecimento, contatos e dinheiro no bolso que investem em Startup.
} 
b) prestação de aporte financeiro por meio de seed money geralmente em troca de participação acionária;

c) foco em equipes pequenas e não fundadores individuais;

d) apoio em tempo limitado, geralmente de 3 (três) à 6 (seis) meses;

e) orientação e seleção de startups por meio de classes, ao invés de empresas individuais.

Seguindo uma linha mais estruturada à incubação de empresas de base tecnológica, a demanda por programas de aceleração têm muitas vezes superado a oferta. Sua ascensão está intimamente ligada às atuais mudanças do cenário empreendedor. Para Fishback et al. (2007, p. 7), a indústria de investimento está em um constante estado de fluxo e renovação, onde o que se observa é uma progressiva diminuição dos custos associados ao início de carreira de startups e pouco tempo para fazer o projeto de negócio "decolar" efetivamente.

Além disso, identificando o alto potencial de crescimento dessas empresas de investimento o Governo Federal Brasileiro em parceria com o Ministério de Ciência, Tecnologia e Inovação (MCTI), o Conselho Nacional de Desenvolvimento Científico e Tecnológico (CNPq) e o TI Maior, desenvolveu o chamado Start-Up Brasil . Um Programa Estratégico de Software e Serviços de TI que tem como objetivo principal propiciar a criação de um ambiente favorável ao desenvolvimento acelerado de empresas nascentes. Em linhas gerais, o programa seleciona aceleradoras de diversas partes do país para que componham um time de aceleração que orientará de forma efetiva startups dos mais variados seguimentos.

\subsection{Lean Startup}

Como já visto, para alcançar sucesso e sobreviverem às primeiras fases do negócio onde os riscos são maiores, muito se tem buscado por métodos eficazes para o desenvolvimento de startups. De acordo com Ries (2012) e Blank (2013) em um ecossistema empreendedor constantemente mutável como o atual, com maiores riscos e incertezas, os tradicionais métodos de gestão não são eficazes, pois se baseiam em previsões, funcionando melhor em ambientes estáticos. Sobre essa perspectiva, a metodologia Lean Startup tem se tornado cada vez mais popular no ambiente da inovação e do empreendedorismo. Inspirado no processo "lean manufacturing ${ }^{10 \prime \prime}$ idealizado pela Toyota e aplicado no setor automotivo de produção, o conceito Lean ou "enxuto" preconizado por Eric Ries e Steve Blank representa um conjunto de novas práticas para criação de empresas nascentes.

Formulado a partir da combinação de ideias de marketing, gestão e tecnologia, a metodologia Lean configura um novo empírico método focado na redução do desperdício (tempo, custo ou recursos) para a construção de produtos e serviços inovadores que levem à um negócio sustentável. Segundo Blank e Dorf (2012) muitas startups quebram na fase inicial principalmente por dedicarem seu tempo a desenvolver produtos ou serviços que "ninguém quer". Dessa forma, o método enxuto traz a perspectiva de um desenvolvimento mais ágil voltado para aprendizagem. Pela validação de hipóteses na busca por um negócio escalável e repetível por meio da experimentação e de feedbacks contínuos com o cliente (RIES, 2012) a fim de conferir ao produto

${ }^{10}$ Manufatura enxuta. 
ou serviço maior qualidade e um time-to-market mais rápido. Assim, o conceito Lean adota 5 (cinco) premissas básicas características da chamada "startup enxuta" (RIES, 2012):

a) empreendedores estão por toda parte: seja numa garagem ou grandes corporações, 0 conceito de empreendedorismo inclui qualquer pessoa que trabalha dentro da definição de startup, ou seja, que tenha o objetivo de criar produtos e serviços a partir de um ambiente de extrema incerteza;

b) empreender é administrar: muito além do produto ou serviço à ser criado, uma startup é uma instituição e como tal deve ser gerida. Sua gestão deve ser orientada especificadamente ao contexto de incertezas da qual se encontra, exigindo um novo tipo de administração, diferente dos métodos tradicionais;

c) aprendizado validado: a existência de uma startup não se restringe apenas a criar produtos ou serviços, gerar receita e servir a seus clientes, elas existem com o objetivo de aprender a desenvolver negócios sustentáveis. Essa aprendizagem pode ser validada de forma científica, pela experimentação constante, testando cada hipótese ou elemento de sua visão;

d) construir-medir-aprender (build-measure-learn): a atividade principal de uma startup é transformar ideias em produtos ou serviços, medir como os clientes respondem a eles, e então, utilizar esse conhecimento como base para determinar quando fazer alterações (pivotar) ou perseverar;

e) contabilidade para inovação: para potencializar os resultados do negócio e melhorar o desempenho dos empreendedores faz-se necessário medir e contabilizar os dados, de forma a avaliar e mensurar o progresso da startup, definir marcos e priorizar seu trabalho.

Estreantes no mercado e inseridas em um ambiente de intensa incerteza, a visão de uma startup em estágio inicial representa apenas um conjunto de hipóteses (NIGRI; MONTEIRO, 2014). Partindo desse pressuposto, ao assumir a existência de hipóteses ao invés de fatos, qualquer novo elemento deve ser testado e validado pelos clientes. De acordo com Blank (2013), para empresas iniciantes não existem fatos conhecidos, grande parte dos planos de negócio não sobrevivem ao primeiro contado com o cliente. Assim, para que haja a validação efetiva das hipóteses, se faz necessário ir à campo de forma a buscar respostas "fora do escritório" (BLANK; DORF, 2012).

Com o objetivo de unir as cinco premissas da startup enxuta, o ciclo de feedback configura o elemento central da metodologia Lean Startup. De forma cíclica e iterativa baseada nos princípios "Build-Measure-Learn", permite validar cada hipótese do processo de desenvolvimento de um produto ou serviço. Permitindo assim, compreender os desejos e aspirações do cliente, o que ele de fato necessita.

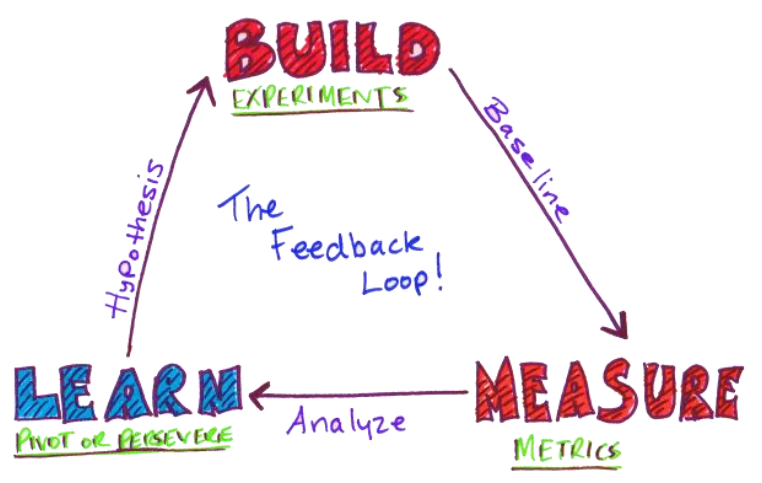

Figura I - Ciclo de Feedback (Build- Measure-Learn)

Fonte: Ries (2012). 
Conforme demonstra figura acima, o ciclo de feedback se inicia a partir da concepção da ideia. Segundo Ries (2012) o processo de caracterização da ideia se dá por meio da descrição, onde serão definidas a visão e os perfis dos possíveis consumidores, que originarão as hipóteses de valor e crescimento. Essas hipóteses tem o objetivo de identificar se o produto ou serviço é capaz de fornecer valor aos usuários e se seu crescimento está dentro das expectativas esperadas (RIES, 2012). Elaborado pela própria empresa, o roteiro de hipóteses configura uma espécie de mapa onde são selecionadas as hipóteses mais criticas do processo que servirão como base norteadora para a pesquisa de mercado (CARVALHO, 2012 apud TORALLES; DULTRA 2014). Objetivo do ciclo é permitir o desenvolvimento do produto de forma veloz e responsiva, onde cada hipótese de valor e crescimento deve ser testada por meio de ciclos curtos que se repetem para obter uma aprendizagem validada em um mínimo espaço de tempo total.

Para tal, a startup deve desenvolver seu MVP. Ele consiste em um tipo de protótipo de rápido desenvolvimento e baixo custo que possui as "features ${ }^{11 "}$ mínimas necessárias para o teste de alguma hipótese do modelo de negócios (BLANK; DORF, 2012 apud NIGRI; MONTEIRO, 2014). É considerado o elemento chave para dar inicio ao processo de aprendizagem Build- Measure-Learn. Gitahy (2014) alerta que o MPV está intimamente relacionado à proposição de valor de uma startup. Dessa forma, não deve ser encarado somente como uma entrega do produto com funcionalidades simplificadas, e sim equilibrar os conceitos de: algo que represente valor pelo cliente (Viable), utilizando menor número de custos em um curto espaço tempo (Product) para que a entrega se assemelhe a um produto (Minimum) e não em uma elaborada e densa lista de funcionalidades para uso. A ênfase desse processo está na agilidade e na velocidade, com que o novo empreendimento cria com rapidez um produto mínimo viável e busca imediatamente a opinião do cliente BLANK (2013, p. 05). Simples ou mais elaborados, esses testes podem constituir até protótipos reais, que têm como finalidade principal provar a veracidade das até então hipóteses desenvolvidas.

Após a realização dos testes com MVP, se inicia o processo de análise, onde os dados colhidos são analisados com o objetivo de medir e avaliar os "insights" ${ }^{12 "}$ obtidos de forma a determinar a efetividade e progresso do modelo adotado pela startup. Com base nos subsídios colhidos, a startup então revê suas hipóteses e inicia novamente o ciclo, testando versões reformuladas e voltando a fazer pequenos ajustes (iterações) ou mudanças mais radicais (o chamado "pivotar") em ideias que não estão funcionando. O pivot consiste na realização específica de mudanças nas estratégias do modelo adotado. Segundo Gitahy (2014), o conceito de "pivotar" para uma startup está em girar em outra direção e testar novas hipóteses, mas mantendo sua base para não perder a posição já conquistada. Assim, caso haja necessidade, a orientação é voltar ao passo anterior a fim de novamente realizar a sequência das outras iterações. Para Ries (2012) o sucesso de uma startup está diretamente ligado a rápida realização do ciclo de feedback. Isso permite maior agilidade na busca por um modelo de negócios efetivo e um menor desperdício de tempo e recursos.

Para atingir a premissa básica da metodologia Lean Startup, aprendizagem validada para a redução de desperdício, faz- se necessário que todos os âmbitos de uma startup estejam alinhados nesse sentido. Sobre essa perspectiva, o setor contábil do novo empreendimento deve exercer

\footnotetext{
${ }^{11}$ Funcionalidades.

12 O insight está relacionado com a capacidade de discernimento, pode ser descrito como uma espécie de epifania.
} 
papel decisivo na orientação do empreendedor para determinar o quanto seus produtos ou serviços estão evoluindo equiparados ao seu aprendizado. Maurya (2012) aponta cinco pontos essenciais sobre o desenvolvimento da contabilidade voltada à inovação:

a) definir um padrão para as métricas estabelecidas pela startup;

b) mesurar tudo por meio de cohorts ${ }^{13}$;

c) monitorar todo o ciclo de vida do cliente, focando em uma métrica única com vistas à sua otimização;

d) validar hipóteses rapidamente através da criação de um ciclo de feedback contínuo com o cliente;

e) trabalhar não apenas baseado em métricas, mas também capitando dados qualitativos com o objetivo de obter insights acerca do produto ou serviço oferecido pela startup e o comportamentos de seus clientes.

Sobre essa perspectiva, do ponto de vista da execução, o conceito enxuto se utiliza da aplicação de diversos métodos ágeis de desenvolvimento propriamente ajustados ao ambiente das startups. Tais metodologias têm como objetivo principal a redução dos ciclos de iteração, com vistas à otimização de tempo e recursos. Onde de forma rápida e incremental, o novo produto ou serviço é desenvolvido e apresentado ao cliente paralelamente à sua construção. Ries (2012) afirma que, se tratando da metodologia Lean Startup, a adoção de métodos de desenvolvimento ágeis é fundamental, pois contribui para uma entrega de software mais rápida e um curto espaço de tempo.

Assim, desenvolvimento ágil é orientado nos seguintes valores principais:

a) foco em indivíduos e suas interações muito mais do que em processos;

b) priorização do funcionamento do software propriamente dito, não se detendo apenas à documentação abrangente;

c) colaboração com o cliente mais do que negociação de contratos;

d) responder prontamente às mudanças muito além do que seguir o próprio plano. (AGIL MANIFESTO, 2001)

Entre os principais métodos ágeis utilizados para o desenvolvimento de projetos estão:

a) extreme programming (XP): metodologia dinâmica de desenvolvimento de software, nascida nos Estados Unidos por volta dos anos 90 baseada em comportamentos e atitudes. Onde a partir de um conjunto de valores: comunicação, feedback, simplicidade, coragem e respeito são definidos 14 princípios que resultam em 24 práticas concretas utilizadas no dia-a-dia da startup para criar e otimizar novos sistemas de projetos.

b) scrum: criado por Jeff Sutherland, esta metodologia é baseada na divisão do projeto em ciclos iterativos (sprints), reuniões constante com a equipe de planejamento (sprint planning meeting/daily scrum) e o desenvolvimento e priorização das funcionalidades (product backlog) do sistema à ser implementado.

\footnotetext{
${ }^{13}$ A palavra cohort se refere a "grupo".
} 
c) kanban: implementado originalmente pela toyota, é uma abordagem gerencial de projetos, que permite a visualização prática do andamento do processo de desenvolvimento de software. No kanban as atividades são divididas em executadas, à executar, em andamento e finalizadas.

\subsubsection{Custumer Development}

Introduzido de forma detalhada por Steve Blank, em sua obra The Four Steps to Epiphany (2012), Custumer Development configura um novo importante método para o desenvolvimento e gestão de startups focado na compreensão dos problemas e necessidades do cliente. Aplicado de forma paralela ao processo de desenvolvimento do produto, o modelo de desenvolvimento de clientes separa todas as atividades relacionadas a clientes nos estágios iniciais de uma empresa, dentro seus próprios processos, em quatro etapas distintas: descoberta de clientes, validação pelo cliente, geração de demanda e estruturação do negócio (BLANK, 2012).

Representadas na figura abaixo, cada etapa do processo de desenvolvimento de clientes ocorre por meio de ciclos bem definidos e realizados de forma iterativa, ou seja, passível de repetição. Dessa forma, para que se possa evoluir para o passo seguinte, faz-se necessário que as "deliverables" de cada estágio sejam cumpridas. Caso contrário, a startup deverá realizar um "pivot" e retroceder ao estágio anterior. Blank (2012) aponta que durante o processo de desenvolvimento de clientes é natural que hajam iterações em cada um dos quatros ciclos. Ele explica que nessa metodologia, "[...] a startup se mantém girando em cada uma das etapas até que conquiste a velocidade de escape, gerando conhecimento suficiente para conduzi-la ao próximo passo" (BLANK, 2012, p. 32). Ries (2012 apud. Toralles e Dultra 2014) afirma que entre os processos de desenvolvimento do produto e desenvolvimento do cliente o ciclo de feedbacks é de importância fundamental.

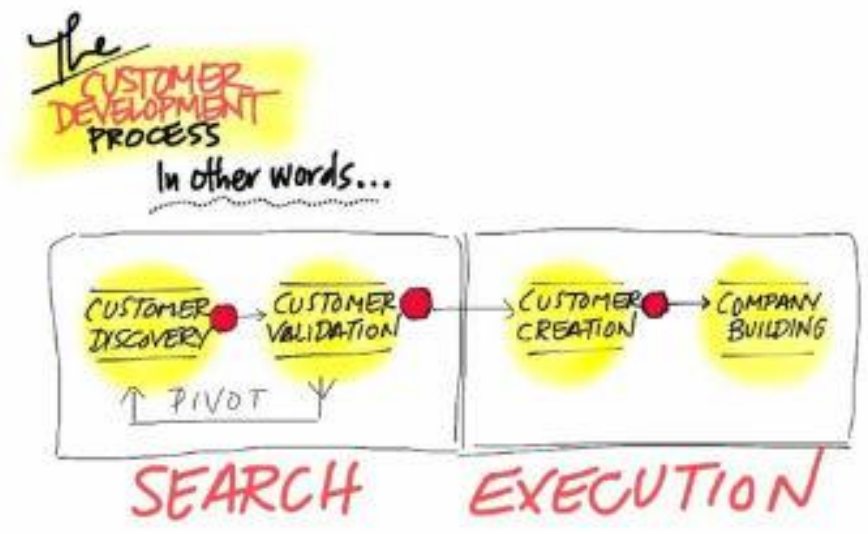

Figura II: Modelo de Desenvolvimento de Clientes Fonte: Blank (2013).

Sobre essa perspectiva, o modelo de desenvolvimento de clientes compreende duas fases específicas: aprendizado e execução. As duas primeiras etapas são dedicadas à aprendizagem. Nessa fase, a startup deve procurar por um modelo de negócios á ser validado de forma ágil e 
mantendo os baixos custos até que encontre seu "Product/Market Fit 14 ". Os investimentos então vão sendo realizados de acordo com os patamares de aprendizado. Não obstante, os dois últimos ciclos são inteiramente focados na execução, onde após definir o "Product/Market Fit" e um modelo de negócios validado e escalável de vendas, a nova empresa passa a aplicar seus esforços no rápido crescimento do negócio.

a) descoberta do cliente: Nessa etapa, os empreendedores transformam a visão do modelo de negócios em hipóteses, como o objetivo de submetê-las a experimentação para que posteriormente sejam validadas.

b) validação pelo cliente: $O$ ciclo de validação pelo cliente representa o ponto de verificação chave que marca a transição da fase de aprendizado à execução. O objetivo dessa etapa é construir um mapa de vendas replicável pelas equipes de marketing e vendas. Esse mapa configura uma espécie de cartilha do processo de vendas que foi comprovado e testado a campo com sucesso durante a venda do produto para os primeiros usuários.

c) geração de demanda: Estruturada a partir do sucesso alcançado nas primeiras vendas, a geração de demanda consiste na condução da demanda à ser gerada por usuários finais ao canal de vendas da empresa (BLANK, 2012). Nessa fase, a startup busca desenvolver uma serie de atividades para que esteja apta até o lançamento.

d) estruturação do negócio: Nessa etapa final, voltada totalmente a execução, são estruturados os departamentos de vendas, marketing e desenvolvimento de negócios, que estarão orientados à missão de alcançarem o sucesso nos primeiros anos de vida da empresa.

\subsubsection{Business Model Generation}

Para que seja aplicado o método enxuto, faz-se necessário a adoção de um efetivo modelo de negócios. Muitas vezes, o insucesso de novos empreendimentos está relacionado à falta de conhecimento acerca do que seria e como funciona um modelo eficiente. Apesar de exigido por parte da maioria dos investidores, o tradicional plano de negócios em muitos casos nem chega a ser lido. Além disso, "[...] ele raramente sobrevive ao primeiro contato com o cliente" (BLANK, 2013, p.05). Para Blank e Dorf (2012) o modelo de negócios desenvolvido por Alexander e Osterwalder (2010) denominado "Canvas" é o que mais se adequa aos conceitos e necessidades da metodologia lean startup. Desenvolvido de maneira simplificada e intuitiva, o Business Model Canvas permite uma visão enxuta do negócio demonstrada em uma única página, sem que sejam deixados de lado, os distintos aspectos de uma empresa.

Dividido em 9 (nove) pilares (segmentos de clientes; proposta de valor; canais; relacionamento com o cliente; fluxo de receitas; recursos chave; atividades chave; parceiros chave; estrutura de custos), o modelo permite demonstrar e definir uma serie de hipóteses a serem testadas à cada componente de forma compartilhada, facilitando discussões e o entendimento acerca do futuro da nova empresa. A figura abaixo demonstra como se apresentam cada um dos blocos que compõem o Canvas do modelo de negócios.

\footnotetext{
14 Product-Market-fit é um termo do universo empreendedor utilizado para descrever o momento em que o empreendedor consegue enxergar um bom mercado e lançar um produto que satisfaça as necessidades do cliente, de forma a encontrar a união perfeita entre o produto/solução proposta e um nicho de mercado promissor.
} 


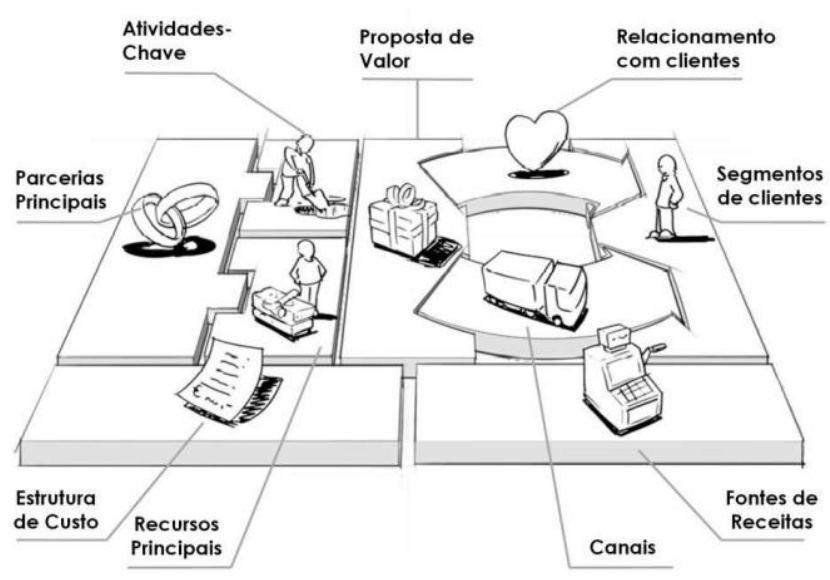

Figura III: Business Model Canvas Fonte: Alexander e Osterwalder (2010).

a) segmento de clientes: Esse bloco é voltado à identificar quem a empresa irá atender, sejam grupos de pessoas ou outras organizações. Assim, de acordo com suas características, necessidades e comportamentos, cada grupo de clientes deve ser agrupado em segmentos distintos. De acordo com Alexander e Osterwalder (2010) além da ideia do negócio faz-se necessário que os empreendedores tenham uma visão consciente para enxergar quem está realmente disposto a pagar e utilizar o novo produto ou serviço. Esses segmentos podem ser de deferentes tipos, tais como: mercado de massa, nicho de mercado, segmentado, diversificado ou multifacetado.

b) proposta de valor: A proposta de valor da empresa deve descrever de forma sucinta a capacidade dos novos produtos ou serviços de gerar valor, ou seja, o conjunto de benefícios que serão entregues aos clientes e que configuram os diferenciais de uma companhia em detrimento a outra. As propostas de valor podem ser de caráter tanto quantitativo ou qualitativo quanto tangíveis e intangíveis.

c) canais: Têm como objetivo descrever os meios pelos quais a nova empresa irá interagir com os clientes para oferecer sua proposta de valor. Representam todos os elementos relacionados à interface empresa/cliente, sejam eles: comunicação, vendas, distribuição entre outros. De acordo com Alexander e Osterwalder (2010), esses canais podem ser próprios ou de parceiros, diretos ou indiretos, sendo subdivididos em cinco fases distintas (conhecimento, avaliação, compra, entrega e pós-venda), das quais podem ser cobertas por um ou mais canais simultaneamente.

d) relacionamento com cliente: Este bloco representa os tipos de relação que a nova empresa pretende desenvolver com seus clientes, sejam estes para atrai-los, como para retê-los e assim aumentar sua receita. Para cada segmento específico a empresa deverá formular uma estratégia de relacionamento, que poderá variar entre pessoal até automatizado.

e) fluxo de receitas: $O$ fluxo de receitas deve descrever os valores monetários gerados a cada segmento específico de clientes. Para tal, a empresa deve determinar o perfil de compra do cliente, ou seja, quanto eles estão dispostos a pagar pelo novo produto ou serviço, quais formas de pagamento preferem e como isso influenciará nas receitas da empresa. Para então, estabelecer as formas de pagamento que irá adotar. Essas receitas podem ser geradas de duas fontes principais: pagamentos à vista ou pagamentos recorrentes, aqueles à serem realizados no futuro com o objetivo de gerar alguma proposta de valor ou prover suporte pós-venda. 
f) recursos chave: Nesse bloco a nova empresa deve identificar precisamente quais são os ativos necessários para o negócio "decolar". Visa o claro entendimento dos recursos que a empresa precisará dispor para criar e obter sua proposta de valor, alcançar mercados, manter relações com os segmentos de clientes e obter receitas. Esses ativos podem ser físicos, financeiros, intelectuais ou humanos e estar presentes tanto internamente, quanto adquiridos através de parceiros.

g) atividades chave: Devem determinar quais são as atividades essenciais relacionadas aos processos cotidianos da empresa para que o modelo de negócios funcione efetivamente. As principais atividades chave citadas no Business Model Generation são: de produção, resolução de problemas e plataforma/rede.

h) parceiros chave: Os parceiros chave têm com objetivo definir quem serão os principais parceiros dos quais a empresa poderá contar para entregar valor a seus clientes. Nesse bloco toda as tarefas e processos operacionais referentes ao andamento do novo empreendimento devem ser claramente mapeados. Segundo Alexander e Osterwalder (2010) existem quatro tipologias de parcerias: as alianças estratégicas entre nãocompetidores, alianças estratégicas entre competidores, joint-ventures para desenvolvimento de um novo negócio, e relacionamento comprador-fornecedor para assegurar a confiabilidade do fornecimento.

i) estrutura de custos: Este ultimo bloco é dedicado à descrição objetiva dos principais custos de caráter financeiro necessários à operacionalização do modelo de negócios, ou seja, os custos mais importantes que incidirão na execução das operações da empresa. A estrutura de custos está dividida em duas categorias distintas: orientação por custos, com objetivo a máxima redução de custos e orientação por valor agregado com foco especifico no valor agregado do novo produto ou serviço para satisfação do usuário (ALEXANDER E OSTERWALDER, 2010).

\section{METODOLOGIA}

O desenvolvimento desse trabalho baseou-se nos dados obtidos por meio de pesquisas e embasamento teórico, que permitiram a obtenção e o tratamento de informações, com o objetivo de encontrar respostas e auxiliar no entendimento da problemática instituída. De acordo com os objetivos propostos, a metodologia utilizada para o desenvolvimento dessa pesquisa é do tipo exploratória e descritiva ou explicativa, já que consistem na identificação da problemática, levantamento bibliográfico e aplicação prática dos conceitos que foram analisados e descritos no projeto. Além disso, a escolha da metodologia de pesquisa está também associada ao caráter inovador do tema a ser pesquisado, a procura por um entendimento geral e maior aproximação com o problema de pesquisa (GIL, 2002).

Ao que se refere à estratégia de pesquisa, foi adotado o estudo de caso único que segundo César (1999) configura uma abordagem qualitativa comumente utilizada para coleta de dados na área organizacional. Sobre essa perspectiva, Yin (2005) apresenta três situações das quais o estudo de caso pode ser aplicado: quando o caso a ser estudado é crítico, para se testar uma hipótese ou teoria explicitada; pela sua singularidade; ou por seu caráter revelador, quando o pesquisador tem acesso a um evento ou fenômeno até então inacessível à pesquisa científica. Considerando que os objetivos dessa pesquisa estão relacionados à análise, identificação e verificação de aspectos característicos do fenômeno investigativo, foi utilizada a metodologia qualitativa. Dessa forma, a 
escolha do procedimento adequado às características do estudo e tipologia de investigação, além das circunstâncias para a aplicação da pesquisa, foi a entrevista.

Foi realizada então, uma entrevista semiestruturada com o objetivo à coleta de dados. Essas conversas foram gravadas e as informações transcritas, sendo o conteúdo submetido a um processo de análise e tratamento qualitativo, onde as informações mais relevantes foram escolhidas, interpretadas e categorizadas em 3 (três) etapas específicas: a) Visão, b) Direção e c) Aceleração, com a finalidade de obter uma abordagem lógica a cerca da verificação da aplicabilidade da metodologia lean startup descrita pela fundamentação teórica desta pesquisa:

a) visão: Representa a visão inicial da startup assim como suas motivações na busca pela "coisa certa a criar". Uma identificação precisa do problema do qual à nova empresa se propõe a resolver e definição de uma solução capaz de entregar valor aos clientes;

b) direção: Envolve todos os atributos relacionados à execução, medição e avaliação da startup, na busca por um modelo de negócios repetível e escalável;

c) aceleração: Refere-se a fase de maturação da nova empresa, quando à mesma ganha escalabilidade e busca alcançar um patamar de crescimento contínuo e sustentável.

Dessa forma, para melhor responder as inquietações propostas no presente estudo sob a perspectiva científica, cada prática e elemento aderente ao método lean startup foi mapeado e relacionado ao longo de cada uma das categorias de análise apresentadas no quadro a seguir, onde os resultados possibilitaram a elaboração do relatório final desta pesquisa, posteriormente apresentado.

Quadro I - Critérios e categorias de análise para verificação da aplicabilidade da metodologia Lean Startup

\begin{tabular}{|c|c|c|}
\hline $\begin{array}{c}\text { Categoria de } \\
\text { Análise }\end{array}$ & Critério & Referências \\
\hline Visão & $\begin{array}{c}\text { Idéia/Motivação; } \\
\text { Definição do problema/solução. }\end{array}$ & $\begin{array}{c}\text { Barbieri (1999) Blank (2008); Drucker } \\
\text { (2001); Hill e Powers (1999). }\end{array}$ \\
\hline Direção & $\begin{array}{l}\text { MVP; Ciclo de feedback; } \\
\text { Validação de hipóteses; } \\
\text { Aprendizagem Validada; } \\
\text { product market fit } \\
\text { Custumer development; Pivot; } \\
\text { Desenvolvimento Ágil; } \\
\text { Contabilidade para Inovação; } \\
\text { Modelo de Negócios (Canvas). }\end{array}$ & $\begin{array}{l}\text { Blank (2014); Blank e Dorf (2012); Ries } \\
\text { (2012); Osterwalder e Pigneur (2009). }\end{array}$ \\
\hline Aceleração & Escalabilidade. & Blank (2014); Ries (2012). \\
\hline
\end{tabular}

Fonte: $O$ autor deste trabalho (2016).

\section{APRESENTAÇÃO E ANÁLISE DOS RESULTADOS}

Esta seção é dedicada a apresentação e análise das informações obtidas a partir da coleta de dados realizada com a aceleradora de negócios 85 Labs, em conjunto com a teoria de base apresentada. Conforme citado, foi feita uma entrevista semiestruturada com um dos fundadores da aceleradora, onde foram abordadas questões abertas com a finalidade de corresponder aos objetivos propostos nesse estudo. 


\subsection{Visão}

Pioneira no Ceará em aceleração de negócios digitais, a 85 Labs iniciou suas atividades em 2014 , com foco em projetos de T.I preferencialmente voltados ao mercado B2B. Com um processo de aceleração médio de 5 (cinco) meses até o demo day, a aceleradora tem como objetivo principal catalisar startups com grande potencial de desenvolvimento e inovação através da qualidade na gestão e ambiente criativo, oferecendo o aporte de financeiro de até 45 (quarenta e cinco) mil reais além de serviços diversos de assessoria em troca de participação acionária de $18 \%$. Voltada a desenvolver negócios viáveis com rápido poder de retorno de capital, a 85 Labs conta com metodologia própria definida da fase pré-operacional até todo o processo de aceleração. No primeiro momento, ela consiste em um processo de seleção aberta, chamada de lançamento e workshops para troca de informações e nivelamento. Assim, as startups com potencial são selecionadas de forma interna pela equipe da aceleradora, que inicia etapas de entrevista onde permanecerão as melhores ideias de negócios que são apresentadas a toda equipe conjuntamente aos investidores para sprint de teste e decisão final.

De acordo com a aceleradora o ponto fundamental para a decisão final do processo de seleção é o capital humano, o que eles chamam de "time". Conforme corrobora Barbieri (1999) e Hill e Powers (1999), não adianta ser detentor de uma boa ideia quando não se é capaz de executála. O concerne da ideia inovadora está em contribuir de maneira efetiva para mercado e seus consumidores (DRUCKER, 2002). Dessa forma, a equipe de trabalho é essencial para o sucesso do projeto. Sobre isso, o entrevistado aponta que, baseado em experiências anteriores em processos de seleção de pré-aceleração, onde são selecionados projetos ainda na fase da ideia, existe maior dificuldade em trabalhar a dedicação dos empreendedores. Assim, é importante que eles amadureçam sua equipe e suas afirmações junto ao mercado para então iniciar o processo de aceleração. Para auxiliar nessa etapa decisiva, a aceleradora oferece conteúdos gratuitos de aprendizagem.

Com o intuito de perceber a sinergia da equipe e sua capacidade de entrega, a 85 Labs realiza uma série de testes que duram cerca de 2 a 4 semanas com o objetivo de aprofundar a relação com os novos empreendedores e avaliar o poder de entrega da equipe. Segundo Blank (2012) muitas startups quebram na fase inicial principalmente por dedicarem seu tempo a desenvolver produtos ou serviços que "ninguém quer". Assim, nessa etapa, as startups devem ter em mente a clara definição da motivação pela qual elas existem, o problema de mercado que pretendem resolver e sua solução.

\subsection{Direção}

Para que o processo de aceleração se inicie efetivamente faz-se necessário que as startups no momento inicial, apresentem a aceleradora seu protótipo funcional, o que Ries (2012) e Blank (2013) denominam por MVP. Os mesmos autores apontam que a construção do MVP é considerada como elemento chave para dar inicio ao processo de aprendizagem Build- MeasureLearn descrito pela metodologia Lean startup. Nesse sentido, os empreendedores devem mostrar que possuem um projeto bem definido cujo problema de mercado tem real relevância e proposição de solução interessante, testada pelos early adopters, os primeiros adotantes do projeto. 
De acordo com o fundador da aceleradora é fundamental que as startups possuam esse entendimento prévio, mesmo que posteriormente algumas características do projeto inevitavelmente mudem, o que é definido pelo método enxuto como "pivot". Segundo Gitahy (2014), o conceito de "pivotar" para uma startup está em girar em outra direção e testar novas hipóteses, mas mantendo sua base para não perder a posição já conquistada. Com o apoio e orientação dos mentores da aceleradora as startups aprimoram e definem suas hipóteses de valor e crescimento. A definição dessas hipóteses compõem o chamado ciclo de feedback e tem o objetivo de identificar se o produto ou serviço é capaz de fornecer valor aos usuários e se seu crescimento está dentro das expectativas esperadas (RIES, 2012).

Sobre essa relação de mentoria da aceleradora com as startups Miller e Bound (2011) apontam que um dos papeis mais importantes nesse relacionamento é a capacidade do "mentoring" de desafiar as equipes e dar-lhes um feedback honesto sobre onde eles estão indo certo e errado. 0 fundador da 85 Labs indaga que o processo de aprendizagem é sempre mútuo. Cada startup passa de fase em fase em tempos diferentes e se tratando de mercados distintos, os testes também têm resultados diferentes, representando um novo aprendizado à cada teste. Para tal, a equipe da aceleradora orienta os novos empreendedores a medirem e priorizarem seu trabalho para que, o quanto antes possam fazer seus testes.

Medir o progresso, definir metas e priorizar o trabalho são as principais premissas que Ries (2012) conceitua como "contabilidade para inovação". Além disso, ao longo de toda metodologia enxuta, "measure" representa um ponto focal para validação do aprendizado. Nesse sentido, para reduzir os ciclos de iteração, com vistas à otimização de tempo e recursos, a adoção de métodos de desenvolvimento ágeis é fundamental, pois contribui para uma entrega de software mais rápida e um curto espaço de tempo (RIES, 2012). Como no kanban, onde as atividades são divididas em: executadas, a executar, em andamento e finalizadas.

Assim, para a aceleradora todo o esforço da startup deve ser voltado à buscar rapidamente o primeiro contato com o cliente. Para tal a 85 Labs trabalha o tema "aquisição de clientes" desde a fase inicial com os empreendedores, o objetivo é que eles obtenham o feedback rápido dos primeiros usuários e possam desenvolver melhoramentos no novo produto com maior agilidade até alcançaram seu product market fit. Sobre isso, Blank (2012) preconizador do método Custumer Development corrobora afirmando que para descobrir se as hipóteses estão corretas é preciso deixa as atividades de adivinhação e sair da empresa com o objetivo de aprender quais são os problemas importantes para o cliente, o que especificadamente do produto soluciona esses pontos, para assim, definir com exatidão quem são esses clientes e usuários. Adepta dessa metodologia, a aceleradora orienta que as startups foquem nesse primeiro contato mesmo antes de desenvolver o MPV.

De acordo com Ries (2012) o concierge é considerado na metodologia lean startup como uma tipologia do MVP que consiste em fazer de maneira manual o que o produto faria automaticamente. Seu objetivo é que a automatização dos processos ocorra de forma incremental e continuada, conforme as hipóteses são validadas. O fundador da aceleradora aponta que a ideia central é fazer com que os próprios empreendedores saiam em busca desses contatos ou desenvolvam essa captação via web. Porém nos casos em que o mercado é muito específico a equipe da aceleradora intervém junto à eles, criando portais e expandindo o network. "As aceleradoras possuem alianças com outras empresas específicas com as quais elas estão 
familiarizadas e possuem boas referências" (CASEMIRO et al. 2014, p.02). Assim, essas conexões muitas vezes representam o "elo" que faltava para inserção de novas empresas no ecossistema empreendedor.

Além disso, para melhor orientar as startups no processo de desenvolvimento em termos de execução, a 85 Labs segue sua própria linha de orientação que abrange os principais métodos utilizados atualmente para o ambiente de inovação. A ferramenta Business Model Canvas de Alexander Osterwalder e Yves Pigneur é comumente usada no dia-a-dia da aceleradora. Assim como outras versões desse modelo de negócios, tais como a Value Proposition Design ${ }^{15}$ dos mesmos autores e a ferramenta Lean Canvas $^{16}$ idealizada por Ash Maurya. Ao que refere ao marketing para aquisição de clientes, a 85 Labs conta com planilhas de experimentos em Growth Hacker $^{17}$, amplamente utilizado pelas empresas de software do Vale do Silício para alcançar escalabilidade em número de usuários, bem como as técnicas de Customer Develpment e análise MoSCoW ${ }^{18}$ de priorização.

Segundo o entrevistado na maioria das vezes os empreendedores desconhecem esses métodos, por isso, existe um esforço maior da aceleradora em desenvolver workshops, plataformas web de educação e mentorias especializadas com o objetivo de orienta-los nas questões próprias do negócio. Por esse motivo, um recente estudo da Harvard Business School desenvolvido por Shikhar Ghosh aponta que $75 \%$ dos novos empreendimentos não vingam (BLANK, 2014). Assim, faz-se necessário o envolvimento ativo da aceleradora no dia a dia das startups. Para tal, a 85 Labs possui uma metodologia robusta, composta por plataformas de acompanhamento e gestão de projetos. Nessas plataformas é possível descrever reuniões, inserir notas de benchmarking ${ }^{19}$ e depositar arquivos. Paralelo a isso, através dos indicadores de performance as startups podem acompanhar cada etapa de sua evolução em diversas planilhas específicas.

\subsection{Aceleração}

A aceleradora que iniciou suas atividades em 2014 aponta que vivencia um momento de "tração", onde a primeira turma de aceleração foi lançada em março de 2014 e iniciou efetivamente em julho do mesmo ano. Assim, as startups aceleradas pela 85 Labs ainda estão em processo de estruturação para alcançar maturidade e então, escalar seu negócio. O fundador da aceleradora explica que o universo de aceleração é muito novo e não possui um modelo específico. Ele aponta que o modelo à ser utilizado deve se adaptar a cultura da região na qual se está atuando

\footnotetext{
${ }^{15}$ Chamado de "Canvas da Proposta de Valor", é uma ferramenta de desenvolvimento de clientes que tem como objetivo promover um maior detalhamento dos blocos segmentos de clientes e proposta de valor do Business Model Canvas tradicional;

16 Lean Canvas é uma técnica inspirada na ferramenta Business Model Canvas que tem como objetivo auxiliar na definição e no refinamento ágil de um modelo de negócios. A ferramenta propõe a alteração de 4 dos 9 itens que compõe o Canvas tradicional para dar foco aos fatores de maior risco em startups;

17 Growth hacking é um conceito novo que traduz uma maneira dinâmica e inteligente de ter ideias e soluções para crescimento de produtos, marcas e experiência com usuários por meio da gestão inovadora de dados e tecnologia no ambiente digital, a fim de perseguir novas formas de utilizar estratégias, informações e interações em favor do desenvolvimento de negócios.

18 É uma técnica para ajudar na priorização de requisitos do projeto, onde o acrônimo MoSCoW refere-se à: MUST: requisitos que devem estar presentes no negócio; SHOULD: requisitos que devem ser considerados ao máximo, mas que não impactam no sucesso do projeto; COULD: requisitos á incluir caso não afetem as necessidades do projeto; WOULD: requisitos a incluir posteriormente ou em futuros desenvolvimentos;

${ }^{19}$ Processo de avaliação da empresa em relação à concorrência, por meio do qual incorpora os melhores desempenhos de outras firmas e/ou aperfeiçoa os seus próprios métodos.
} 
e acima de tudo é fundamental testa-lo constantemente com a finalidade de sempre ajusta-lo. Não obstante, existem muitas outras questões a se considerar, como variáveis externas, os riscos do próprio negócio e o comprometimento dos empreendedores: "Às vezes o modelo de negócios é bom, o mercado é bom, as metodologias por trás mais são bem robustas, então dá pra o pessoal trabalhar bem... mas se o time não quiser o negócio não acontece mesmo".

Segundo o entrevistado esse é um ponto muito importante. "Existe muito mercado com muita dor que precisa ser resolvida e que os empreendedores não vão atrás". Na maioria das vezes os novos empreendedores ficam restritos a buscar soluções apenas para os problemas típicos do seu cotidiano. "Tem muita gente criando startup por que é bacana e não tá resolvendo problema relevante... isso não é só culpa dos empreendedores porque você pensa nos problemas que você vive". Assim, ele acredita que faz-se necessário ir à campo e observar outras perspectivas com vistas à propor soluções reais para outros seguimentos distintos, que anseiam por mudanças.

Outro ponto comentado pelo entrevistado foi à maturidade do empreendedor. Ele aponta que esse aspecto faz toda a diferença. Com os atuais exemplos de startups bem sucedidas como: Facebook, Peixe Urbano, Groupon, ContaAzul e Easy Taxi, muitos novos empreendedores se sentiram inspirados a iniciarem seus projetos. Porém é importante ter a compreensão do quão desafiador e responsivo isso significa. Ries (2012) conceitua startup como "uma instituição humana desenhada para criar um novo produto ou serviço em condições de extrema incerteza". Assim, lidar com um ecossistema de negócios constantemente mutável como o atual, com maiores riscos e incertezas requer acima tudo dedicação e persistência. Além de compreender a necessidade de uma cultura de trabalho continuada.

\section{CONSIDERAÇÕES FINAIS}

O A análise da presente pesquisa sobre o tema "O papel das aceleradoras na consolidação de novas empresas de cultura empreendedora a luz da metodologia Lean Startup" permitiu através do estudo da fundamentação teórica e interpretação das informações obtidas a partir da coleta de dados realizada com a aceleradora de negócios 85 Labs responderam de forma satisfatória aos objetivos propostos nesse estudo. Do ponto de vista teórico foi possível compilar uma bibliografia consistente acerca da metodologia lean startup, mesmo constatando que há pouca literatura acadêmica disponível sobre o tema. Do ponto de vista prático verificou-se a direta aplicabilidade desse método, permitindo compreender como cada elemento que o compõem se apresenta no decorrer da descrição de cada etapa do processo de aceleração das startups. Além de descrever como se dá o processo de aceleração de negócios, a análise da pesquisa possibilitou identificar que as principais dificuldades enfrentadas pelas startups no decorrer do ciclo de aceleração do ponto de vista da aceleradora estão relacionadas a falta de experiência dos empreendedores em negócios e a dificuldade na utilização de uma abordagem científica, com a aplicação de metodologias no processo.

A cerca dos benefícios resultantes da relação startup - aceleradora, foi percebido que a aprendizagem mútua configura o mais importante deles, assim como a disponibilidade de orientação empresarial, o acesso a investidores e a criação de networking. Constatou-se então, que as aceleradoras de negócios exercem um papel decisivo no desenvolvimento e consolidação de novas empresas de cultura empreendedora, visto que o processo de aceleração direciona e capacita as startups principalmente nas primeiras etapas do negócio, onde os riscos são 
consideravelmente maiores. Não obstante, a contribuição da metodologia lean startup ficou evidente em todas as fases do ciclo de aceleração, o que permite afirmar sua capacidade em conduzir processos estruturados de aceleração em negócios com eficácia em caso real. Também foi possível perceber através da análise do estudo de caso específico, que outras técnicas e ferramentas de gestão são agregadas a utilização do método lean. O que significa afirmar que para alcançar o sucesso na aceleração de startups, cada aceleradora determina os melhores métodos que irá utilizar, desenvolvendo sua própria metodologia sob a ótica da inovação e do empreendedorismo.

\section{REFERÊNCIAS}

1. ARISTÓTELES. Ética a Nicômaco. São Paulo: Abril Cultural, 1984.

2. ASSOCIAÇÃO BRASILEIRA DE STARTUPS. O que é uma startup. São Paulo, 2015. Disponível em: <http://www.abstartups.com.br/o-que-e-uma-startup/>. Acesso em: 3 dez. 2015.

3. BARBIERI, José Carlos. Os inventores no Brasil: Tipos e modalidade de incentivos. Revista de Administração de Empresas, São Paulo: v. 39, n.2, p. 54-63, abr/jun. 1999.

4. BARREHAG, Lisa et al. Accelerating Success: A Study of Seed Accelerators and Their Defining Characteristics. 2012. Tese (Licenciatura em Engenharia e Gestão Industrial) - Chalmers University of Technology, Gotemburgo, Suécia, 2012.

5. BLANK, S; DORF, B. The Startup Owner's Manual. Ed. Alta Books, 2012.

6. BLANK, S. Why the lean start-up changes everything. Harvard business Review, Canadá: mai. 2013. Disponível em: <http://www.vto.at/wpcontent/uploads/2013/10/Why-the-LeanStartup-Changes-Everything_S.Plank_HBR-052013.pdf>. Acesso em: 2 dez. 2014.

7. The Four Steps to Epiphany. Ed. Évora, 2012.

8. CASEMIRO, P; W. de PAULA; O. SIENA; C. ANDRÉ. Orientação Empreendedora e Aceleração de Negócios: Fatores, Processos e A Consolidação de Negócios Digitais. In: ENCONTRO DE ESTUDOS SOBRE EMPREENDEDORISMO E GESTÃO DE PEQUENAS EMPRESAS, 8., Anais. Goiania: mar. 2014.

9. CESAR, Ana Maria. Método do Estudo de Caso (Case Studies) ou Método do Caso (Teaching Cases)? Uma análise dos dois métodos no Ensino e Pesquisa em Administração. 2010. Disponível em: <http://www.mackenzie.br/fileadmin/Graduacao/CCSA/remac/jul_dez_05/06 .pdf>. Acesso em: 2 dez. 2014.

10. CONSELHO REGIONAL DE ADMINISTRAÇÃO DE SÃO PAULO. Mentoring. São Paulo, 2015. Disponível em: <http://www.crasp.gov.br/crasp/centro/interna.aspx?secao_id=245\&campo =1683>. Acesso em: 2 dez. 2014.

11. DORNELAS. Empreendedorismo: Transformando ideias em negócios. 2. ed. Rio de Janeiro. Rio de Janeiro: Campus, 2001.

12. DRUCKER, P. F. Inovação e Espírito Empreendedor: Prática e princípios. Ed. Thomson Pioneira. São Paulo, 2002.

13. FISHBACK, B. et al. Finding Business "Idols": A New Model to Accelerate Start-Ups. Ewing Marion Kauffman Foundation. Kansas, 2007. Disponível em: <http://sites.kauffman.org/pdf/ 
Finding_Business_Idols.pdf>. Acesso em: 2 dez. 2014.

14. GIL, Antonio Carlos. Como Elaborar projetos de pesquisa. 4 ed. São Paulo: Atlas, 2002.

15. GITAHY, Yuri. Por que você deve pivotar sua startup, 2016.Disponível em: <http://www.se brae.com.br/sites/PortalSebrae/artigos/Por-que-voc\%C3\%AA-deve-pivotar-sua-startup>. Acesso em: 3 dez. 2014.

16. Global Entrepreneurship Monitor - GEM. London, 2013. Disponível em: <http://www.gemcon sortium.org/docs/3106/gem-2013-global-report>. Acesso em: 3 dez. 2014.

17. GUSTAFSSON, A.; QVILLBERG, J. Implementing lean startup methodology - an evaluation. Dissertação. Chalmers University of Technology. Suécia, 2012. Disponível em: <<http://publications.lib.chalmers.se/records/fulltext/164603.pdf>>. Acesso em: 3 dez. 2015.

18. HILL, Napoleon; POWERS, Melvin. Think and Grow Rich. Ed. Wilshire Book Co, 1999.

19. KOTLER, P. Marketing. 3 ed. São Paulo: Editora Atlas, 1986.

20. LAKATOS, Maria Eva; MARCONI, Maria de Andrade. Metodologia do trabalho científico. 4 ed. São Paulo: Revista Ampliada, Atlas, 1992.

21. Manifesto Ágil. 2011. Disponível em: <http://agilemanifesto.org/>. Acesso em: 3 dez. 2014.

22. MAURYA, Ash. Running Lean: Iterate from Plan A to a Plan That Works. ed. O'Reilly Media, Inc. 2012.

23. MILLER, P; BOUND, K. The Startup Factories: The rise of accelerator programmes to support new technology ventures. London: Nesta, 2011.

24. MUSSAK, Eugênio. Uma boa idéia não é tudo. São Paulo, 2012. Disponível em: <http://eugeniomussak.com.br/uma-boa-ideia-nao-e-tudo/>. Acesso em: 3 dez. 2014.

25. NIGRI, R. M. ; MONTEIRO, P. V. C. Estudo de caso da aplicação do Customer Development a uma startup digital de educação. Monografia (Graduação em Engenharia de Produção) Universidade Federal do Rio de Janeiro, 2014. Disponível em: <monografias.poli.ufrj.br/ monografias/monopoli10010063.pdf>. Acesso em: 3 dez. 2014.

26. OSTERWALDER, A.; PIGNEUR, Y.; Business Model Generation: A Handbook for Visionaries, Game Changers, and Challengers. Toronto: Self Published, 2010

27. PATEL, Neil. 9 Metrics to Help You Make Wise Decisions About Your Start-Up. Disponível em: <http://blog.kissmetrics.com/9-metrics/>. Acesso em: 2 dez. 2014.

28. RIES, Eric. A startup enxuta: Como os Empreendedores Atuais Utilizam a Inovação Contínua para Criar Empresas Extremamente Bem-sucedidas. São Paulo: Lua de Papel, 2012.

29. RIBEIRO, Elisa Antônia. A perspectiva da entrevista na investigação qualitativa. Evidência: olhares e pesquisa em saberes educacionais. Minas Gerais: Fundação Cultural de Araxá, v.4, n.4, 129-148. 2008.

30. RIVOLI, P. As viagens de uma T-Shirt no mercado global. Lisboa: Editorial Presença, 2005.

31. SEVERINO, Antonio Joaquim. Metodologia do trabalho científico. São Paulo: Cortez, 2007

32. TORALLES, P. Rodrigo, DULTRA, P. M. Marcelo. A relevância do desenvolvimento do cliente para o desenvolvimento de produtos inovadores. SEPA, Salvador: UNIFACS, V.13, P.334-350. 2014. Disponível em: <http://www.revistas.unifacs.br/index.php/sepa/article/view/3394>. 
Acesso em: 3 dez. 2014.

33. VICTORAZZO, Ville et al. Análise da escalabilidade em novos negócios. Revista FATEC, Sebrae em Debate, São Paulo: FATEC, Sebrae, v.1, n.1, p129-148. 2014. Disponível em: <http://revista.fatecsebrae.edu.br/index.php/em_debate/article/view/19>. Acesso em: 3 dez. 2014.

34. YIN, Robert K. Estudo de caso: planejamento de métodos. Porto Alegre: Bookman, 2005. 